\title{
Association between Musculoskeletal Pain in Japanese Construction Workers and Job, Age, Alcohol Consumption, and Smoking
}

\author{
Satoru UENO ${ }^{1 *}$, Naomi HISANAGA ${ }^{1}$, Hiroshi JONAI ${ }^{1}$, \\ Eiji SHIBATA $^{2}$ and Michihiro KAMIJIMA ${ }^{3}$
}

\author{
${ }^{1}$ National Institute of Industrial Health, 6-21-1, Nagao, Tama-ku, Kawasaki 214-8585, Japan \\ ${ }^{2}$ Department of Medical Technology, Nagoya University School of Health Sciences, 1-1-20, Daiko-minami, \\ Higashi-ku, Nagoya 461-8673, Japan \\ ${ }^{3}$ Department of Occupational and Environmental Health, Nagoya University Graduate School of Medicine, 65, \\ Tsurumai-cho, Showa-ku, Nagoya 466-8550, Japan
}

Received October 26, 1998 and accepted August 30, 1999

\begin{abstract}
A cross-sectional epidemiologic study was conducted to determine the prevalence of selfreported musculoskeletal pain (MSP) in construction workers and identify associations between MSP and individual factors (i.e., job, age, alcohol consumption, and smoking). The prevalence of total hand/arm pain (T-HAP), total shoulder pain (T-SP), and total low-back pain (T-LBP) was $\mathbf{2 8 . 4} \%, \mathbf{2 8 . 7} \%$, and $\mathbf{5 3 . 2 \%}$, respectively. Risk factors for total pain and for relatively severe pain in the hand/arm (RS-HAP), shoulder (RS-SP), and low-back (RS-LBP) were estimated by multiple logistic regression analysis. The results showed that musculoskeletal pain was significantly associated with age, and that the odds ratios (ORs) for relatively severe musculoskeletal pain increased almost linearly with age. Regarding job, compared with architects whose work is presumed to be sedentary, almost all ORs for T-HAP, T-SP, and T-LBP for non-sedentary construction jobs were significantly high. Current smokers of 20 cigarettes a day or more had significantly higher ORs for RS-HAP and RS-LBP than "never smokers". We suppose that 1) total and relatively severe pain were associated with age, 2) non-sedentary work was at higher risk of total MSP than sedentary work, and 3) heavy smoking contributed to RS-LBP.
\end{abstract}

Key words: Construction worker, Hand/arm pain, Shoulder pain, Low back pain, Age, Smoking, Crosssectional

\section{Introduction}

Musculoskeletal pain (MSP) is one of the most common occupational health problems, and workers in the construction industry are at high risk of MSP. In 1996, the Japanese Ministry of Labor reported that low back pain (LBP) is the primary (about 60\%) cause of occupational sick leave for 4 days or more and that the construction industry has the second

*To whom correspondence should be addressed. largest business area in terms of number of patients ${ }^{1)}$. In the US, a nationwide health interview survey showed that construction workers are the highest risk group for workrelated $\mathrm{LBP}^{2}$. A Dutch study showed that non-sedentary workers, such as construction workers and plumbers, have a relatively higher prevalence of LBP, whereas sedentary workers have a lower prevalence ${ }^{3)}$. Whereas construction workers belong to high-risk groups for MSP, there have been few reports ${ }^{4,5)}$ on MSP in construction workers. There are wide variety of jobs in the construction industry, e.g., 
carpentry, plastering, and plumbing; nevertheless, little has been discovered about risk factors according to jobs.

In Japan, $64 \%$ of construction workers are employed by enterprises that have fewer than 30 employees ${ }^{6}$, making it difficult to provide them with sufficient occupational health services. Accordingly, it is important to grasp the actual conditions of MSP and make clear its causes. This paper reports the results of a questionnaire survey to determine the prevalence of MSP in the construction industry and associations between MSP and job, age, alcohol consumption, and smoking.

\section{Materials and Methods}

\section{Subjects}

A construction workers' health insurance society in Mie Prefecture, Japan, has been conducting annual health checkup examinations since the 1970s. In 1995, 3,567 males undertook the examination among approximately 16,000 insured male workers (workers employed at small-scale enterprises, 23.8\%; self-employed, 76.2\%) ${ }^{7)}$. A selfadministered questionnaire survey was conducted on all of the examinees at the time of the annual health check-up, and $2,899(81.3 \%)$ responded completely to our questionnaire. The "complete" respondents comprised 1,166 carpenters (40.2\%), 206 plasterers (7.1\%), 192 electricians (6.6\%), and others (Table 1). The mean age of all respondents was 44.7 years, ranging from 34.0 for interior finish workers to 49.5 for plasterers. Out of the 2,899 "complete" respondents, 2,289 workers belonging to 10 main jobs were chosen as subjects of this study.

\section{Questionnaire}

All of the examinees were asked about job, age, alcohol consumption, smoking, and whether or not they have hand/ arm pain (HAP), shoulder pain (SP), or LBP. The severity of recent pain was classified into five grades as follows: 1) severe, receiving medical treatment; 2) severe, but not receiving medical treatment; 3) moderate, but not receiving medical treatment; 4) mild, but not receiving medical treatment; and 5) none.

\section{Analysis}

Logistic regression analysis was employed to investigate the relationships between explanatory variables ( job, age, alcohol consumption, and smoking ) and outcome variables ( HAP, SP, and LBP). To minimize bias derived from differences in the size of the categories, we divided each explanatory variable into as equal strata as possible in terms of number. Age was categorized into quintiles as follows: 20-33 ( $n=468), 34-42 \quad(n=479), 43-48 \quad(n=470), 49-56$ $(n=446)$, and 57-70 $(n=426)$ years old. Alcohol consumption was classified by frequency as follows: drink rarely or not at all $(n=686), 1-6$ days a week $(n=515)$, every day $(n=1,088)$. Smoking was categorized as follows: never smoker ( $n=366)$, ex-smoker $(n=506)$, currently smoking 19 cigarettes a day or less $(n=760)$, and currently smoking 20 cigarettes a day or more $(n=657)$. We used dummy variables by the partial method in the calculations and defined architect as the reference group for job, the youngest stratum for age, drinking rarely or not at all for alcohol consumption, and never smokers for smoking.

With regard to outcome variables, the following three categories: 1) severe, receiving medical treatment; 2) severe,

Table 1. Number and mean age of respondents by job

\begin{tabular}{lrrr}
\hline \multicolumn{1}{c}{ Job } & Number of respondents & $\%$ & Age (Mean \pm SD) \\
\hline Carpenter & 1166 & $40.2 \%$ & $46.8 \pm 11.6$ \\
Plasterer & 206 & $7.1 \%$ & $49.5 \pm 9.5$ \\
Electrician & 192 & $6.6 \%$ & $39.8 \pm 11.1$ \\
Interior finish worker & 142 & $4.9 \%$ & $34.0 \pm 10.4$ \\
Steel-frame worker & 130 & $4.5 \%$ & $45.5 \pm 11.9$ \\
Plumber & 119 & $4.1 \%$ & $42.4 \pm 11.8$ \\
Sheet metal worker & 98 & $3.4 \%$ & $41.9 \pm 11.6$ \\
Architect & 84 & $2.9 \%$ & $39.1 \pm 10.9$ \\
Painter & 78 & $2.7 \%$ & $41.9 \pm 8.2$ \\
Laborer & 74 & $2.5 \%$ & $47.1 \pm 11.4$ \\
Others & 610 & $21.0 \%$ & $44.8 \pm 12.4$ \\
\hline Total & 2899 & $100 \%$ & $44.7 \pm 12.0$ \\
\hline
\end{tabular}


but not receiving medical treatment; and 3) moderate, but not receiving medical treatment; were lumped into "relatively severe pain". "Relatively severe pain" plus 4) mild, but not receiving medical treatment were considered "total pain". Accordingly, we used two methods of dichotomizing three ordinal scales of pain as follows: having pain or not, and having relatively severe pain or not.

P-values, the indices to acceptability of the null hypothesis that the regression coefficient of each category within the same factor was 0 , were calculated based on Wald test statistics ${ }^{8}$. Namely, they represented the connection between each explanatory variable and the pain in each part of the body. Furthermore, odds ratios (ORs) were calculated for each outcome variable with confidence intervals $(95 \% \mathrm{CI})$ based on $\chi^{2}$ test statistics.

To test the associations between outcome variables, we used four-fold point correlation coefficient ( $\phi$ coefficient ) for carpenters, since they represented the largest of 10 jobs. Their outcomes were dichotomized into total pain and no pain to calculate the coefficient.

The data were analyzed with Microsoft Access 97 and Excel 97 software (Microsoft Corporation) on a personal computer and SAS/STAT software ver. 6.11 (SAS Institute Inc.) on S-4/5 (Fujitsu). A logit link function was used in the model with the module PROC LOGISTIC in the SAS statistical software.

\section{Results}

Fig. 1 shows the prevalence of total pain by job. Average prevalence was $28.4 \%$ for total HAP (T-HAP), $28.7 \%$ for

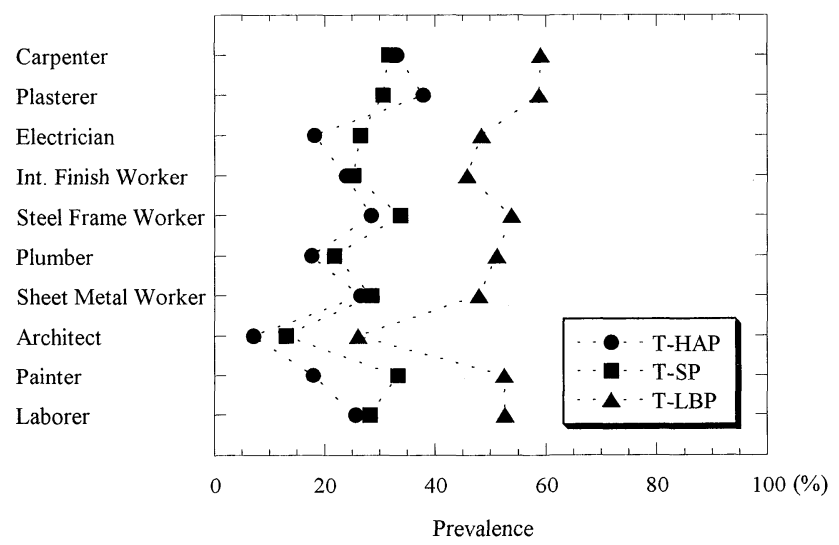

Fig. 1. Prevalence of musculoskeletal pain by job.

T-HAP: Having hand/arm pain, T-SP: Having shoulder pain, T-LBP: Having low back pain, Int. Finish Worker: Interior finish worker. total SP (T-SP), and $53.2 \%$ for total LBP (T-LBP). The prevalence of T-LBP was larger than that of T-SP or T-HAP in every job. Architects had the lowest prevalence for every pain variable. The distribution of the prevalence of total pain by age is shown in Fig. 2. The prevalence of T-HAP, T-SP, and T-LBP increased with age until 50-54, 50-54, and 45-49 years old, respectively, and then tended to decrease. The prevalence of T-LBP was larger than that of T-HAP or T-SP in every age category.

We then performed logistic regression analysis to search for associations between outcome variables and explanatory variables. The results for T-HAP, T-SP, and T-LBP are listed in Table 2. Among the factors analyzed, Wald test statistics ( $p$-values) showed that job was significant for T-HAP and T-LBP, and that age was significant for T-HAP, T-SP, and TLBP. From $\chi^{2}$ test statistics (ORs), all jobs were significantly related to three T-MSPs, except plumber (TSP), laborer (T-SP), and painter (T-HAP). In terms of age, the risk of T-HAP and T-SP rose until 49-56 years and declined at 57 years and older, whereas the risk of T-LBP increased until 34-42 years and decreased thereafter. Alcohol consumption and smoking were not significant risk factors for total pain.

The associations between relatively severe pain and the explanatory variables were different from those of total pain (Table 3). Wald test statistics (p-values) indicated that age was a significant factor for relatively severe HAP (RS-HAP), relatively severe SP (RS-SP), and relatively severe LBP (RSLBP), and that smoking was a significant factor for RSLBP. Job did not significantly affect RS-HAP, RS-SP, or

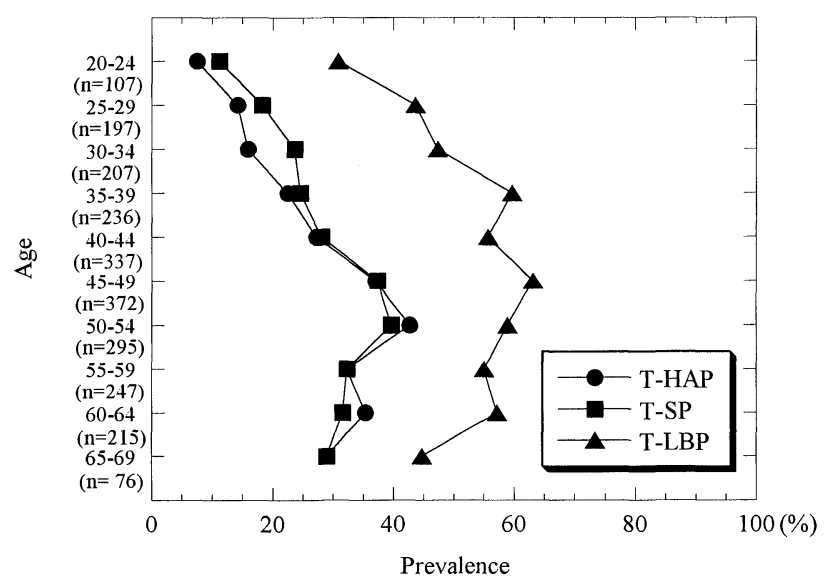

Fig. 2. Prevalence of musculoskeletal pain by age.

T-HAP: Having hand/arm pain, T-SP: Having shoulder pain, T-LBP: Having low back pain. 
Table 2. Results of multiple logistic analysis (Total pain)

\begin{tabular}{|c|c|c|c|c|c|c|c|c|c|}
\hline \multirow[b]{2}{*}{ Factors: variables } & \multicolumn{3}{|c|}{ Hand/Arm Pain } & \multicolumn{3}{|c|}{ Shoulder Pain } & \multicolumn{3}{|c|}{ Low Back Pain } \\
\hline & OR & $(95 \% \mathrm{CI})$ & P-Value & OR & $(95 \% \mathrm{CI})$ & P-Value & OR & $(95 \% \mathrm{CI})$ & P-Value \\
\hline Job: & & & 0.00 & & & 0.08 & & & 0.00 \\
\hline Architect & 1 & & & 1 & & & 1 & & \\
\hline Carpenter & 6.47 & $(2.64-21.42)$ & & 2.60 & $(1.34-5.67)$ & & 3.68 & $(2.15-6.68)$ & \\
\hline Plasterer & 6.89 & $(2.68-23.45)$ & & 2.12 & $(1.02-4.88)$ & & 3.31 & $(1.82-6.33)$ & \\
\hline Electrician & 3.10 & $(1.15-10.83)$ & & 2.48 & $(1.19-5.70)$ & & 3.11 & $(1.70-5.94)$ & \\
\hline Int. finish worker & 6.92 & $(2.56-24.24)$ & & 2.49 & $(1.14-5.93)$ & & 3.08 & $(1.63-6.05)$ & \\
\hline Steel-frame worker & 4.37 & $(1.60-15.40)$ & & 2.42 & $(1.12-5.71)$ & & 3.04 & $(1.60-6.01)$ & \\
\hline Plumber & 3.02 & $(1.05-10.94)$ & & 1.67 & $(0.74-4.06)$ & & 3.00 & $(1.57-5.97)$ & \\
\hline Sheet metal worker & 5.48 & $(1.97-19.50)$ & & 2.63 & $(1.18-6.35)$ & & 2.83 & $(1.45-5.74)$ & \\
\hline Painter & 2.64 & $(0.82-10.15)$ & & 3.42 & $(1.50-8.40)$ & & 3.84 & $(1.91-7.96)$ & \\
\hline Laborer & 3.82 & $(1.27-14.18)$ & & 1.39 & $(0.55-3.65)$ & & 2.90 & $(1.42-6.11)$ & \\
\hline Age: & & & 0.00 & & & 0.00 & & & 0.00 \\
\hline $20-33$ & 1 & & & 1 & & & 1 & & \\
\hline $34-42$ & 1.71 & $(1.16-2.56)$ & & 1.38 & $(0.96-1.97)$ & & 1.59 & $(1.20-2.11)$ & \\
\hline $43-48$ & 2.89 & $(1.98-4.26)$ & & 2.11 & $(1.49-2.99)$ & & 1.51 & $(1.14-2.01)$ & \\
\hline $49-56$ & 3.05 & $(2.09-4.52)$ & & 2.43 & $(1.72-3.47)$ & & 1.34 & $(1.00-1.79)$ & \\
\hline $57-70$ & 1.91 & $(1.29-2.86)$ & & 1.65 & $(1.15-2.38)$ & & 0.96 & $(0.72-1.30)$ & \\
\hline Alcohol: & & & 0.47 & & & 0.20 & & & 0.55 \\
\hline Rarely or none & 1 & & & 1 & & & 1 & & \\
\hline 1-6 days a week & 1.11 & $(0.88-1.42)$ & & 1.19 & $(0.94-1.51)$ & & 0.95 & $(0.78-1.16)$ & \\
\hline Every day & 0.96 & $(0.72-1.28)$ & & 1.27 & $(0.96-1.67)$ & & 1.07 & $(0.85-1.36)$ & \\
\hline Smoking: & & & 0.92 & & & 0.46 & & & 0.34 \\
\hline Never smokers & 1 & & & 1 & & & 1 & & \\
\hline Ex-smokers & 0.89 & $(0.65-1.23)$ & & 0.96 & $(0.70-1.31)$ & & 0.95 & $(0.73-1.25)$ & \\
\hline$<20$ cig./day & 0.92 & $(0.67-1.26)$ & & 1.16 & $(0.86-1.57)$ & & 1.13 & $(0.87-1.47)$ & \\
\hline$\geq 20 \mathrm{cig} . / \mathrm{day}$ & 0.92 & $(0.67-1.28)$ & & 0.98 & $(0.71-1.35)$ & & 1.14 & $(0.87-1.52)$ & \\
\hline
\end{tabular}

P-values, the indices to the acceptability of the null hypothesis that the regression coefficient of each category within the same factor was 0 , were calculated based on Wald test statistics. Namely, they represented the connection between each explanatory variable and the pain in each part of the body. Furthermore, odds ratios (ORs) were calculated for each outcome variable with confidence intervals $(95 \% \mathrm{CI})$ based on $\chi^{2}$ test statistics. OR: odd ratio.

RS-LBP. From $\chi^{2}$ test statistics (ORs), with regard to age, the risk of relatively severe pain increased almost linearly with age. Currently smoking 20 cigarettes a day or more brought a significant higher risk of RS-LBP compared with never smokers $(\mathrm{OR}=1.47,95 \% \mathrm{CI} 1.00-2.16)$, whereas currently smoking less than 20 cigarettes a day did not cause a higher risk. Ex-smokers, current smokers of less than 20 cigarettes a day and current smokers of 20 cigarettes or more had a significantly higher risk of RS-HAP than never smokers.

$\Phi$ coefficients, representing the strength of associations between outcome variables, were all positive, and the correlation between T-HAP and T-SP was the strongest $(\phi=0.57)$. Carpenters with some pain in one body region tended to experience pain in other regions (Fig. 3).

\section{Discussion}

Job

In the present study, job alone was considered to estimate exposure to work-related risk factors for MSP. Workers in the same job were assumed to have the same exposure to occupational risk factors. Other occupational factors, such as the number of work days a month, number of hours worked a day, degree of physical activity, and work environment, were not taken into account. Accordingly, real associations between exposure to occupational risk factors and MSP remain unclear ${ }^{9)}$. Nonetheless, some possible associations were detected.

The non-sedentary workers had a higher prevalence of MSP than the sedentary workers. The formers' daily activities 
Table 3. Results of multiple logistic analysis (Relatively severe pain)

\begin{tabular}{|c|c|c|c|c|c|c|c|c|c|}
\hline \multirow[b]{2}{*}{ Factors: variables } & \multicolumn{3}{|c|}{ Hand/Arm Pain } & \multicolumn{3}{|c|}{ Shoulder Pain } & \multicolumn{3}{|c|}{ Low Back Pain } \\
\hline & OR & $(95 \% \mathrm{CI})$ & P-Value & OR & $(95 \% \mathrm{CI})$ & P-Value & OR & $(95 \% \mathrm{CI})$ & P-Value \\
\hline Job: & & & 0.93 & & & 0.29 & & & 0.34 \\
\hline Architect & 1 & & & 1 & & & 1 & & \\
\hline Carpenter & 2.06 & $(0.62-12.83)$ & & 1.92 & $(0.58-11.95)$ & & 2.03 & $(0.93-5.34)$ & \\
\hline Plasterer & 2.11 & $(0.57-13.68)$ & & 2.04 & $(0.54-13.36)$ & & 2.24 & $(0.95-6.20)$ & \\
\hline Electrician & 1.87 & $(0.46-12.58)$ & & 1.27 & $(0.28-8.82)$ & & 1.19 & $(0.47-3.46)$ & \\
\hline Int. finish worker & 2.26 & $(0.46-16.34)$ & & 2.76 & $(0.63-19.06)$ & & 1.42 & $(0.51-4.33)$ & \\
\hline Steel-frame worker & 2.97 & $(0.76-19.73)$ & & 3.25 & $(0.84-21.49)$ & & 2.01 & $(0.80-5.80)$ & \\
\hline Plumber & 1.42 & $(0.29-10.18)$ & & 1.55 & $(0.32-11.09)$ & & 1.77 & $(0.68-5.22)$ & \\
\hline Sheet metal worker & 1.51 & $(0.28-11.25)$ & & 1.16 & $(0.19-9.05)$ & & 1.38 & $(0.49-4.26)$ & \\
\hline Painter & 2.47 & $(0.50-17.91)$ & & 1.49 & $(0.24-11.64)$ & & 1.02 & $(0.31-3.44)$ & \\
\hline Laborer & 2.24 & $(0.49-15.86)$ & & 4.17 & $(1.01-28.31)$ & & 1.80 & $(0.64-5.53)$ & \\
\hline Age: & & & 0.00 & & & 0.00 & & & 0.00 \\
\hline $20-33$ & 1 & & & 1 & & & 1 & & \\
\hline $34-42$ & 3.51 & $(1.23-12.56)$ & & 2.23 & $(0.97-5.56)$ & & 2.42 & $(1.46-4.15)$ & \\
\hline $43-48$ & 9.19 & $(3.55-31.40)$ & & 3.31 & $(1.52-8.05)$ & & 2.84 & $(1.73-4.84)$ & \\
\hline $49-56$ & 10.19 & $(3.94-34.85)$ & & 3.83 & $(1.76-9.30)$ & & 2.69 & $(1.62-4.61)$ & \\
\hline $57-70$ & 12.93 & $(5.02-44.15)$ & & 4.74 & $(2.20-11.45)$ & & 3.65 & $(2.23-6.22)$ & \\
\hline Alcohol: & & & 0.08 & & & 0.99 & & & 0.39 \\
\hline Rarely or none & 1 & & & 1 & & & 1 & & \\
\hline 1-6 days a week & 0.97 & $(0.64-1.48)$ & & 0.97 & $(0.64-1.50)$ & & 1.11 & $(0.78-1.58)$ & \\
\hline Every day & 1.53 & $(0.95-2.45)$ & & 0.98 & $(0.58-1.65)$ & & 1.22 & $(0.92-1.65)$ & \\
\hline Smoking: & & & 0.09 & & & 0.23 & & & 0.04 \\
\hline Never smokers & 1 & & & 1 & & & 1 & & \\
\hline Ex-smokers & 1.90 & $(1.05-3.65)$ & & 1.86 & $(1.01-3.61)$ & & 1.05 & $(0.71-1.58)$ & \\
\hline$<20$ cig./day & 1.87 & $(1.03-3.56)$ & & 1.46 & $(0.78-2.86)$ & & 0.97 & $(0.66-1.45)$ & \\
\hline$\geq 20 \mathrm{cig} . / \mathrm{day}$ & 2.18 & $(1.22-4.12)$ & & 1.77 & $(0.95-3.45)$ & & 1.47 & $(1.00-2.16)$ & \\
\hline
\end{tabular}

P-values, the indices to the acceptability of the null hypothesis that the regression coefficient of each category within the same factor was 0 , were calculated based on Wald test statistics. Namely, they represented the connection between each explanatory variable and the pain in each part of the body. Furthermore, odds ratios (ORs) were calculated for each outcome variable with confidence intervals $(95 \% \mathrm{CI})$ based on $\chi^{2}$ test statistics. OR: odd ratio.

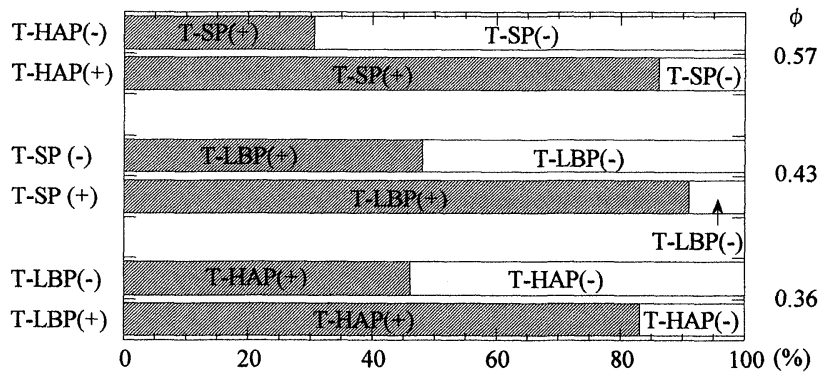

Fig. 3. Relation between types of musculoskeletal pain in carpenters. T-HAP(+): Having hand/arm pain, T-HAP(-): Not having hand/Arm, TSP(+): Having shoulder pain, T-SP(-): Not having shoulder pain, $\mathrm{T}-$ LBP(+): Having low back pain, T-LBP(-): Not having low back pain. The percentages of workers with/without pain in one part of the body among workers with/without pain in another part of the body are shown as $\phi$ indices in the right margin. are supposed to include heavy physical work, e.g. frequent bending, twisting, lifting, and operating hand tools. Job was significantly associated with T-HAP and T-LBP, and the most of the non-sedentary jobs analyzed had significantly higher ORs than architects. These results were consistent with the results of other studies ${ }^{10,11)}$. For relatively severe pain, job did not seem to be a significant risk factor. This might be attributable to the dropout of workers with relatively severe pain and the small sample number of workers with relatively severe pain; the small number led to a large margin of error.

\section{Age}

Age was a risk factor for MSPs in this study as reported in the past ${ }^{12-15)}$, and yet other studies have indicated that 
age is not a significant risk factor for MSPs ${ }^{16-18)}$. Some studies ${ }^{19-20)}$ showed that the risk of age for MSP differed according to the kind of pain or the duration of the pain. The ORs of the youngest stratum were the lowest in this study, but this finding contrasted with other research ${ }^{21)}$ on low back injury; the research indicated that younger age and shorter duration of employment were significant risk factors. It is difficult to compare our results with those of other studies, because the subjects of the study, the questionnaires and the analytical methods have varied from investigation to investigation.

We included employment duration instead of age in our another calculation. Since age and employment term were highly correlated, the results were very similar to those for age. Accordingly, we could not specify which of these variables affected MSP.

From a medical standpoint, bone mineral density ${ }^{22)}$ and muscle strength ${ }^{23)}$ decrease as aging proceeds, and thus workers are assumed to become more susceptible to muskuloskeletal burdens in their senior years. The ill effects of certain occupational activities have been shown to persist many years even after cessation of exposure ${ }^{24)}$, and it seemed possible that the decrease in resistance to injury and accumulation of damage to tissue were responsible for the higher prevalence of relatively severe pain linearly with age, but the prevalence of total pain did not yield a linear correlation with age. We could not explain why the tendency to decrease in the senior age stratum was observed only for total pain.

\section{Alcohol consumption}

Some recent epidemiologic studies about MSPs do not list alcohol consumption as an explanatory variable in analysis, and alcohol abuse was related with deterioration of muscle strength and histological injury to muscle ${ }^{25}$. For this reason, we added alcohol consumption to explanatory variables in calculation. Alcohol consumption was not a significant risk factor for musculoskeletal pain in this study, but another study have shown that alcohol abuse is significantly more frequent among patients with low back pain ${ }^{26)}$.

\section{Smoking}

Some studies ${ }^{13-15,27,28)}$ have reported that smoking is a risk factor for MSP in some regions, and other studies have reported that is not ${ }^{29}$. There was a monotonic dose-response relationship between the current level of smoking and prevalence of back pain ${ }^{30)}$ or prolonged back pain ${ }^{31)}$. Other studies $^{14,15)}$ showed that smoking is significantly related to MSP even after correcting for many factors. In this study, smoking was not associated with total pain but with relatively severe LBP.

No mechanism for the association between smoking and MSP has been established, but some researchers tried to explain the association. One hypothesis is that nicotine reduces the body's blood flow and nutrition supply, negatively affects tissue metabolism ${ }^{32-33)}$, and can increase susceptibility to injury. Another hypothesis is that smoking decreases bone density and leads to a higher risk of fracture ${ }^{34)}$.

It is difficult to conclude that smoking is a risk factor for MSP from the results of a questionnaire study. Smoking is also associated with psychological risk factors, such as job dissatisfaction, lack of social support, job stress ${ }^{35)}$, and daily physical activity ${ }^{36}$. Smoking may not be a direct cause of MSP, but only a confounding factor. Moreover, while smoking may be a cause of MSP, it may also be an effect of MSP. Smoking is thought to induce mood enhancement and may reduce the subjective stress caused by MSP. Workers tend to smoke when they experience MSP ${ }^{27}$. Further study is needed to determine which precedes, smoking or MSP.

\section{Other risk factors}

In this study, explanatory variables were confined to job, age, alcohol consumption, and smoking. According to Dempsey et al. ${ }^{35)}$, history of injury, physical fitness, absolute strength, and psychosocial factors are other risk factors for MSP. Other researchers consider ${ }^{37)}$ that biomechanical factors, such as awkward posture, and prolonged standing or sitting, psychosocial factors, and physical environment are risk factors for MSP. There may be other important risk factors that have not been investigated in this study.

\section{Correlation between painful parts of the body}

The positivity of all $\phi$ coefficients in carpenters showed that workers experiencing pain in one part of the body had a higher probability of suffering pain in other parts of the body. The highest $\phi$ coefficient in carpenters was between T-HAP and T-SP, the medium one was between T-SP and TLBP, and the lowest one was between T-LBP and T-HAP; this indicated that the closer the parts of the body, the greater the correlation between the prevalence of pain in those body parts. This can be attributable to occupational activities or some individual factors.

\section{Acknowledgements}

The authors would like to thank the Construction Workers' Health Insurance Society of Mie Prefecture for their 
collaboration and Dr. Yasutaka Ogawa of the National Institute of Industrial Health for his valuable discussions.

\section{Reference}

1) Yamamoto $S$ (1997) A new trend in the study of low back pain in workplaces. Ind Health 35, 173-85.

2) Guo HR, Tanaka S, Cameron LL, Seligman PJ, Behrens VJ, Ger J, Wild DK, Putz-Anderson V (1995) Back pain among workers in the United States: national estimates and workers at high risk. Am J Ind Med 28, 591-602.

3) Hildebrandt VH (1995) Back pain in the working population: prevalence rates in Dutch trades and professions. Ergonomics 38, 1283-98.

4) Lemasters GK, Atterbury MR, Booth-Jones AD, Bhattacharya A, Ollila-Glenn N, Forrester C, Forst L (1998) Prevalence of work related musculoskeletal disorders in active union carpenters. Occup Environ Med 55, 421-7.

5) Yoshida T, Goto M, Nagira T, Ono A, Fujita I, Goda S, Bando M (1971) Studies on low back pain among workers in small scale construction companies Report 1. Analysis of clinical and radiological findings. Sangyo Igaku 13, 37-45.

6) The 1996 Establishment and Enterprise Census. Statistics Bureau \& Statistics Center, Management and Cordination Agency of Japan.

7) Hisanaga N, Sakai K, Shibata E, Takeuchi Y (1995) Prevention of asbestos-related disease in small-scale construction industry. Proceedings of the international symposium on occupational health research and practical approaches in small-scale enterprises. 67-75.

8) Kleinbaum DG (1994) Logistic regression-A selflearning, Chapter 5, Springer, New York.

9) Ahlbom A, Steineck G (1992) Aspects of misclassification of confounding factors. Am J Ind Med 21, 107-12.

10) Westgaard RH, Jensen $C$, Hansen $K$ (1993) Individual and work-related risk factors associated with symptoms of musculoskeletal complaints. Int Arch Occup Environ Health 64, 405-13.

11) Xu Y, Bach E, Ørhede E (1997) Work environment and low back pain: the influence of occupational activities. Occup Environ Med 54, 741-5.

12) Fujimura $T$, Yasuda N, Ohara H (1995) Work-related factors of low back pain among nursing aides in nursing homes for the elderly. Sangyo Eiseigaku Zasshi 37, 89-
98.

13) Brage $S$, Bjerkedal $T$ (1996) Musculoskeletal pain and smoking in Norway. J Epidemiol Community Health 50, 166-9.

14) Eriksen WB, Brage S, Bruusgaard D (1997) Does smoking aggravate musculoskeletal pain? Scand J Rheumatol 26, 49-54.

15) Leino-Arjas $P$ (1998) Smoking and musculoskeletal disorders in the metal industry: a prospective study. Occup Environ Med 55, 828-33.

16) Ekberg K, Karlsson M, Axelson O (1995) Crosssectional study of risk factors for symptoms in the neck and shoulder area. Ergonomics 38, 971-80.

17) Ono $Y$, Nakamura $R$, Shimaoka $M$, Hiruta $S$, Hattori Y, Ichihara G, Kamijima M, Takeuchi Y (1998) Epicondylitis among cooks in nursery schools. Occup Environ Med 55, 172-9.

18) Skov T, Borg V, Ørhede E (1996) Psychosocial and physical risk factors for musculoskeletal disorders of the neck, shoulders, and lower back in salespeople. Occup Environ Med 53, 351-6.

19) Lipscomb HJ, Dement JM, Loomis DP, Silverstein B, Kalat J (1997) Surveillance of work-related musculoskeletal injuries among union carpenters. Am J Ind Med 32, 629-40.

20) Leboeuf-Yde C, Lauritsen JM, Lauritzen T (1997) Why has the search for causes of low back pain largely been nonconclusive? Spine 22, 877-81.

21) Daltroy LH, Larson MG, Wright EA, Malspeis $S$, Fossel AH, Ryan J, Zwerling C, Liang MH (1991) A casecontrol study of risk factors for industrial low back injury: implications for primary and secondary prevention programs. Am J Ind Med 20, 505-15.

22) Sinaki M, McPhee MC, Hodgson SF, Merritt JM, Offord KP (1986) Relationship between bone mineral density of spine and strength of back extensors in healthy postmenopausal women. Mayo Clin Proc 61, 116-22.

23) Lindle RS, Metter EJ,Lynch NA, Fleg JL, Fozard JL, Tobin J, Roy TA,Hurley BF (1997) Age and gender comparisons of muscle strength in 654 women and men aged 20-93 yr. J Appl Physiol 83, 1581-7.

24) Sobi A, Cooper C, Inskip H, Searle S, Coggon D (1997) Occupational physical activity and long-term risk of musculoskeletal symptoms: A national survey of post office pensioners. Am J Ind Health 32, 76-83.

25) Estruch R, Sacanella E, Fernandez-Sola J, Nicolas JM, Rubin E, Urbano-Marquez A (1998) Natural history of alcoholic myopathy: a 5-year study. Alcohol Clin 
Exp Res 22, 2023-8.

26) Sandström J, Andersson GB, Wallerstedt S (1984) The role of alcohol abuse in working disability in patients with low back pain. Scand J Rehab Med 16, 147-9.

27) Jamison RN, Stetson BA, Parris WC (1991) The relationship between cigarette smoking and chronic low back pain. Addict Behav 16, 103-10.

28) Holmström EB, Lindell J, Moritz U (1992) Low back and neck/shoulder pain in construction workers: occupational workload and psychosocial risk factors. Part 1: Relationship to low back pain. Spine 17, 66371.

29) Riihimäki $H$, Wickström $G$, Hänninen $K$, Luopajärvi $T$ (1989) Predictors of sciatic pain among concrete reinforcement workers and house painters - a five-year follow-up. Scand J Work Environ Health 15, 415-23.

30) Deyo RA, Bass JE (1989) Lifestyle and low-back pain. The influence of smoking and obesity. Spine 14, 501-6.

31) Leboeuf-Yde C (1996) Does smoking cause low back pain? Results from a population-based study. J Manipulative Physiol Ther 19, 99-108.
32) Frymoyer JW, Pope MH, Clements JH, Wilder DG, MacPherson B, Ashikaga T (1983) Risk factors in lowback pain. An epidemiological survey. J Bone Joint Surg Am 65, 213-8.

33) Borenstein $D$ (1992) Epidemiology, etiology, diagnostic evaluation, and treatment of low back pain. Curr Opin Rheumatol 4, 226-32.

34) Hopper JL, Seeman E (1994) The bone density of female twins discordant for tobacco use. N Engl J Med 330, 387-92.

35) Dempsey PG, Burdorf A, Webster BS (1997) The influence of personal variables on work-related lowback disorders and implications for future research. $\mathrm{J}$ Occup Environ Med 39, 748-59.

36) Gardner AW, Sieminski DJ, Killewich LA (1997) The effect of cigarette smoking on free-living daily physical activity in older claudication patients. Angiology 48, 947-55.

37) Wickström GJ, Pentti J (1998) Occupational factors affecting sick leave attributed to low-back pain. Scand J Work Environ Health 24, 145-52. 